Article

\title{
Assessing Importance of Disaster Preparedness Factors for Sustainable Disaster Risk Management: The Case of the Slovak Republic
}

\author{
Michal Titko *(i) and Jozef Ristvej * \\ Faculty of Security Engineering, Department of Crisis Management, University of Žilina, 01026 Žilina, Slovakia \\ * Correspondence: michal.titko@fbi.uniza.sk (M.T.); jozef.ristvej@fbi.uniza.sk (J.R.)
}

Received: 19 September 2020; Accepted: 26 October 2020; Published: 2 November 2020

\begin{abstract}
Regarding the prognoses of disasters in the future connected with climate change, disaster risk management (DRM) is becoming one of the decisive elements of sustainable development. The possibility of involving the general public to DRM implementation is, currently, a frequently discussed topic. In particular, population preparedness for the involvement of the public is questionable and, therefore, the understanding of the conditions that facilitate public preparedness for disasters is decisive. This article presents the results of research that investigates the factors affecting (1) the objective preparedness of the population, as well as (2) the subjective perception of our preparedness for disasters. The statistical analysis discovered that both sides of the public's preparedness depended especially on their experience with disasters, the awareness of the possible risks and appropriate procedures to solve situations, and the economic potential of the households. The results emphasize the need to support the process of increasing the awareness of risks and the possible preventive procedures that can be carried out before disasters by the public, including the more economically vulnerable groups. In this area, the collaboration of the responsible authorities and general public is very desirable. Therefore, our study and its results can serve as a support for creating the DRM policies and sustainable development.
\end{abstract}

Keywords: disaster; preparedness; sustainable development; disaster risk management; climate change

\section{Introduction}

Today, we frequently hear about the influence and possibilities of disaster risk management (DRM) to achieve objectives of sustainable development [1-3]. It is caused by the fact there are many threats that could negatively impact the realization of these goals through particular disasters. A suitably implemented DRM should prevent these threats and events, reduce the probability of their occurrence, ensure an effective response and preparation for the possible impacts, and also ensure a system of realizing recovery after they cease to exist $[4,5]$. However, the sustainability of realizing and developing this system is dependent on changing conditions that are connected with the globalization processes (e.g., climate change)—an important issue [1,2].

The sustainability of DRM represents an objective that will ensure that DRM can be realized and developed, not only in the current conditions, but also in conditions that are likely to change in the near future. It is assumed that disasters and negative effects connected with climate change will increase in frequency and intensity [6-9]. It is also assumed that the costs for the disasters in connection with the loss of life and damages of the social, economic, and environmental activities will increase $[10,11]$. The DRM should be so flexible that it will be independent of the conditions it is realized in as much as possible. The vigilant approach to the given change would include a whole range of early adaptation 
interventions against the manifestation of the climate crisis [12]. In combination with appropriately designed reaction measures, it will accelerate the recovery of society, and support to manage the damages and the overall renewal more effectively (build back better-BBB) [4]. The iterations of the DRM adjusted in this way will reduce the future risks and will support building a resilient society and its development [13].

It is necessary that the uncertainty in the framework of which the DRM is realized would not become a "stumbling block" of such a system. One of the possibilities is to change the approach of preparing and coping with the crisis phenomena of the event-based approach, to a process-based one, or to choose a certain type of their combination [14]. It is essential for us not to prepare and plan activities only for particular and assumed events, because, in uncertainty, it is a complicated idea to prepare ourselves suitably for particular demonstrations of this phenomenon. We should enhance such a process system that principally does not take into account the type of the event, but ensures that all important tasks that accompany almost every crisis phenomenon are fulfilled. Several approaches incline to the opinion that just the involvement of society (communities, people) to the DRM is the supporting pillar of such an approach in which the sustainable DRM can be built [15-19]. The importance of the public's position is currently emphasized in the frameworks of building a resilient society, reducing people's vulnerability, BBB, etc. $[4,5,20,21]$. Most of them are based on the principle of strengthening the population's preparedness for future disasters [4,5]. Disaster preparedness is an important element of the DRM that can also contribute to achieving the sustainable development goals [17]. In Slovakia we can see an obvious gap in the existing DRM system and the position of the public in its framework is uncertain, especially within the disaster preparedness area [22,23]. The tasks related to the population preparedness for disasters are carried out only in compliance with the duties resulting from the legal regulations and other directives. There are no initiatives, policies, or strategies that focus on improving the resilience of society against disasters, and no initiatives that would lead to any strategic development of the population's preparedness in this area [22,23].

Enhancing the people's disaster preparedness can be achieved mainly by understanding the factors that determine it. For that reason, it is important to make a difference between the objective and subjective preparedness for a disaster $[1,4,24]$. The objective preparedness is understood as the "structural" preparedness, i.e., if people take preventive measures (e.g., if they prepare supplies, take measures to protect their assets, technical measures) against the occurrence of the event [4]. The subjective preparedness is understood as an ability to prepare people's feeling that they are sufficiently prepared for an emergency and its impacts (if they perceive their capacities and abilities to be sufficient) [1]. Currently, the studies of preparedness incline more to the objective measurement of preparedness. Sandanam et al., as well as Schneider, claim that it is critical to understand how people perceive their preparedness (both physical and psychological) and the things that affect it are frequently more important than an objective view-especially when we are speaking about sustainable development and building the DRM system from a long-term point of view [1,24]. This study investigates the disaster preparedness from both perspectives, and is looking for the common determinants of these constructs.

Given that the disasters, especially the climate-related ones, can threaten sustainable development, it is crucial to understand the factors that influence both the people's objective and the subjective preparedness for dealing with a future disaster. Therefore, the main goal of this study is to investigate how the different factors (socioeconomic, experience, awareness-related, and perception-related factors) are related to (1) people's preventive behavior (objective preparedness); and (2) the perception of one's own preparedness (subjective preparedness). In order to investigate the relations between these variables a sample from the Slovak Republic was used.

\section{Risk and Disaster Preparedness}

There are several definitions that specify preparedness of the population for disasters. According to the International Federation of Red Cross (IFRC), disaster preparedness relates to measurers taken 
for preparing and reducing the impacts of the disasters [25]. It means to foresee, and, if possible, to prevent disasters, moderate their effects against the vulnerable population groups, and to respond to their consequences and to solve them efficiently [25]. In the Slovak Republic we understand under the term disaster preparedness theoretical knowledge, practical skills, and habits of self-protection [26]. In other words, they are abilities and capabilities of people to protect themselves and to moderate or avoid the impacts of the crisis phenomenon by themselves, but also to be able to provide aid to the close people and the surroundings [27]. Very similarly, and with a certain rate of concretization, Kitagawa defines preparedness for a wide spectrum of subjects (from the government and state administration through response and recovery organizations, to communities, and individuals). According to her, preparedness can be understood as "knowledge and capacities developed by mentioned subjects to effectively anticipate, respond to and recover from the impacts of disasters" [28]. Taking into account the classification in the introduction-the objective and subjective preparedness-we can see that the definition according to IFRC considers important the objective side of this preparedness. Other definitions state, also, the importance of the subjective side-through the knowledge and certain habits of protection. These basic approaches to assessing preparedness are perceived and described by various authors in a different way and assign different importance levels to the individual preparedness aspects.

Rusell et al. defines the objective preparedness on an example of an earthquake on the basis of three aspects of preparedness: the structural, planning and survival aspects [29]. All three aspects, as a result, speak about taking measures before the situation: (1) the structural aspect-hard (structural) intervention measures (e.g., protection of buildings or adaptation of the surface, structural elements, technologies) [30-32]; (2) the planning aspect-moderate (non-structural) measures (e.g., plans, instructions, policies, communication methods) [30,33]; (3) the survival aspect-it is possible to identify with the authors using different designations (e.g., the capacity aspect) and partially different content (supplies, material resources, information resources, financial reserves, evacuation capacities, etc.) [29]. These capacities should serve the individuals or households for overcoming the time period during which the effects of the disaster will be active and there will be no available common food resources, water, and also, e.g., information. In the framework of the survival aspect or the capacity aspect, it is also possible to speak about the stand-by power supply (the electric torch, aggregates), certain tools, various means or equipment that serve for solving the situation (water pumps, lighting, bags with sand). From the point of view of the evacuation capacities, e.g., Niva et al. include here, also, the physical capability to evacuate or help a family member, friends, community member, or the local government, and professional emergency units with evacuation [34]. The aforementioned individual capabilities are important in cases when the affected territory and community have to rely on their own aid. However, in the cases when the evacuation is necessary, the material commodities will be needed only for a short time period, and afterwards they seem to be little effective. The recovery and return to the given territory can be demanding and the capacities the returnees will need are primarily the financial reserves-the insurance claim or common financial reserves [35-38]. The financial reserves are not only important from the point of view of the possible consequences of the disaster, but also due to any unforeseen expenses of the individual or family $[39,40]$. The creation of such reserves itself but also other types of reserves or realizing various structural and non-structural measures depends especially on the economic possibilities of the person or family. From the viewpoint of this study, we will consider the objective preparedness as a disjunction of the aforementioned factors (at least one aspect is fulfilled/present).

However, the strengthening of the objective preparedness is also given by perceiving the risk by knowledge of people or their awareness of possible threats to their security [14]. Already, Cutter defined the people's perception as a process that connects the individual judgments about the level of danger with activities [41]. The perception of danger and its pre-condition (often investigated by the authors as an estimation of the possibility or probability of appearing disaster in the near future [42], or fear of disasters in the future) can lead to activities improving the level of the people's security [43], i.e., on the 
one hand, the perception of the risk can be based on the objective reasons (there is a real threat-e.g., own experience, knowledge of the local situation, etc.), but on the other hand, it can originate in the fear that something negative can happen (e.g., mediated experience, insufficient or no awareness, no knowledge of implementing the preventive measures, etc.). In this connection, Blockland and Reniers (2020) speak about the quality of perception where the perception quality should be understood as a gap between reality and perception of this reality [14]. The thinner the gap is, the higher the quality of perception we have. It means that the increase of awareness, knowledge, and understanding the links are decisive for improving preparedness, and for strengthening our security [14]. Another aspect of perception of the risk can be seen in the persuasion of the person about his/her ability to organize and carry out the activities that are necessary for achieving the results/goals (known also as self-sufficiency)—in our case, about the ability to prepare successfully for the perceived danger or to overcome the crisis $[44,45]$. Our study perceives just this property as a gauge of the citizens' subjective preparedness.

As we have already mentioned, quality of risk perception based on sufficient knowledge of the risk factors, the methods concerning protection against disasters and procedures of solving the developed events (the risk and disaster awareness) can increase the preparedness level and level of resilience against these phenomena [46]. It means the investigation of disaster perception and especially disaster awareness (what people know about disasters and how they understand them) can reveal an insufficient or erroneous perception of correlations people have in this area [41]. At the same time, it can contribute to clarifying the knowledge shortages (the knowledge of the threat zones, protection measures, the principles how to behave during disasters, etc.) and strengthening the subjective preparedness assessment. The detected facts are subsequently analyzed and we look for the casual links. The appropriate perception and risk awareness of a potential development of a disaster is supported especially by the previous experience of people with these events.

Several authors (e.g., [47-50]) specified how the experience affects the risk or disaster perception by individual persons. The previous experience with disasters forms the expectations of the person about the future disasters and his/her behavior [47,51-53]. There is evidence that the experience with disasters can motivate people to a pro-active, but also reactive behavior and, thus, to taking measures to overcome disasters if they appear. They adopt preventive measures to overcome effects of disasters or to create reserves for survival [47,51-53]. At the same time, disaster experience affects the subjective perception of our preparedness. People will realize which shortages in preparation occurred during the previous event, what they were not prepared for, what could be done in a different way, what was underestimated and they can assess better their capabilities for coping with the future events. Each iteration of this cycle assumes an increase of the preparedness level (both the subjective and objective); however, this does not always happen. The aforementioned statements are not confirmed by all studies and can differentiate according to the type of the investigated initiation event or the stance of the person to the risk on the basis of his/her own interpretation of the knowledge or experience. In some cases, we can even speak about the "experience-adjustment paradox" [53]. Those situations that were weak as to the intensity and destructive force can lead to "incorrect" experience and an erroneous interpretation. Chapman says that conscious emotional experience is a combination of the basic sensational states and a whole range of the cognitive assessments of the context by us and others, as well as the multiple motivation impulses. A subjective view at the preparedness level can be, therefore, distorted [54]. However, the influence of experience and people's knowledge on the objective preparedness (in different forms) is confirmed by majority of studies $[55,56]$. The previous personal experience as a predictor of increasing the subjective preparedness has to be investigated more deeply because this view involves a certain amount of distortion and the assessment of the behavior of a certain sample need not be applicable for other cases.

Various groups of inhabitants regarding their basic socio-economic properties/integration (age, education, income, etc.) and their different vulnerability can be differently prepared, and they are not 
able to cope with the undesirable impacts of disasters at the same level. The research of the influence of these properties was also incorporated to our study.

There are several aspects that are to be solved relevantly and be addressed in the framework of investigating the inhabitants' preparedness for the disaster. The primary analysis shows that several aspects are more or less mutually determined. It is almost impossible to investigate the given aspects and to eliminate this fact in the whole extent and, therefore, the authors are investigating the main aspects of preparedness as a combination of several variables.

\section{Materials and Methods}

\subsection{Study Site}

The Slovak Republic belongs to the countries of Central Europe with a changeable climate during the whole year. The weather changeability causes sudden and strong storms during summer accompanied by high rainfall totals on a small territory and strong winds. During winter, some localities suffer from snow calamities and, subsequently, from floods that are connected with melting snow and ice in spring. It is assumed these phenomena will be more intensive due to the climate changes. Because of this the floods, windstorms, snow calamities, and forest fires occur in Slovakia more frequently nowadays [57]. According to the statistics of the Ministry of Interior of the Slovak Republic, our country recorded 1560 natural disasters during 2013-2019, out of which the floods created more than $70 \%$ [58]. In connection with climate change, there are extreme weather influences-hot weather and droughts (they have been more frequent since 2013) and it is also visible in the neighboring countries (the Czech Republic) and, therefore, preparedness for these events is in the spotlight. Due to the amount of the floods this study aims especially at this phenomenon.

\subsection{Research Methods}

We created a structured, self-administered questionnaire with the goal to investigate the predictors of the objective preventive behavior and also a subjective view at disaster preparedness. The research was realized in the first half of 2019. This study is aimed at the youth and adults; conclusions can be accepted only for these population groups. The interest of the authors to realize the research just in this population group resulted from the fact that they have the biggest chance to participate in changing the DRM system, especially in connection with climate change. Due to that fact, there is no complex framework for investigating the preparedness of the Slovak society (neither the government nor the Ministry of Interior assess the preparedness level of the Slovak population); the questionnaire was distributed through the internet by a direct link to the questionnaire. The questionnaire was distributed to the randomly selected respondents (youth and working people) to randomly chosen e-mail addresses from the list of addresses. The list was created from the student accounts of our university and the lists of acquired e-mail addresses (not the students; we were assigned a permission for sending the questionnaire). The list of the non-student e-mails was obtained by snowball technique-the university students were asked to contact friends or acquaintances with our request to participate in the survey and provide their e-mail addresses for the purpose of the questionnaire link distribution; they could also invite other people to provide an e-mail address. The questionnaire was approved by the faculty top management and the answers were anonymous (the e-mail addresses were not required when completing the questionnaire and were not otherwise paired). We are aware of the fact there is a possible distortion due to the method of selecting the sample; however, the classification of the respondents covers the important population characteristics in the framework of the target population. The size of the sample was calculated for $\mathrm{n}=794$ respondents for the $95 \%$ confidence interval and $3.5 \%$ error of margin. The number of the respondents (n) can be also different because the questionnaire contained also optional questions.

The questionnaire included various types of disasters and extreme weather events (floods, strong winds and storms, snow calamities, extreme hot weather, drought, earthquakes, landslides, 
and forest fires). However, for the purposes of this article, we primarily utilized the results connected with preparedness for floods.

\subsection{Questionnaire Structure and Key Variables}

In the interest of investigating objective and subjective preparedness of the selected part of population for disasters and determinants of this preparedness, we divided the research to three basic groups of information: (a) the basic demographic and socio-economic characteristics of the respondents (gender, age, permanent address, number of disabled people or people requiring higher care in the household, economic situation-independent variables); (b) preparedness aspects: disaster experience, disaster perception disaster awareness (independent variables); (c) basic dependent variables-(1) objective preparedness and (2) subjective preparedness. Table 1 shows the investigated variables.

Table 1. The questionnaire structure concerning the preparedness aspects.

\begin{tabular}{|c|c|c|}
\hline Preparedness Aspect & Main Variables & Response \\
\hline \multicolumn{3}{|c|}{ Dependent variables } \\
\hline Objective preparedness & $\begin{array}{l}\text { Preventive and Mitigation } \\
\text { Measures Adopted }\end{array}$ & $\begin{array}{c}\text { Yes }=1 \text { (description of activity } \\
\text { done }) / \text { no }=0\end{array}$ \\
\hline Subjective preparedness & $\begin{array}{l}\text { Subjective assessment of own } \\
\text { preparedness for disasters }\end{array}$ & $\begin{array}{c}\text { from I am not prepared at all }=1 \text { to } I \\
\text { am very well prepared }=5\end{array}$ \\
\hline \multicolumn{3}{|c|}{ Independent variables } \\
\hline \multirow{3}{*}{ Experience } & Disaster experience (number) & number/frequency \\
\hline & The worst experience & $\begin{array}{l}\text { none or minimal = } 1 \text {; logistic } \\
\text { complications }=2 \text { (transport, } \\
\text { services, etc.); minor damages on } \\
\text { property }=3 \text {; major damages on } \\
\text { property }=4 \text { (including damaged } \\
\text { environment); threats for life and } \\
\text { health }=5\end{array}$ \\
\hline & Evacuation experience & yes $=1 /$ no $=0$ \\
\hline \multirow{4}{*}{ Risk and Disaster Perception } & $\begin{array}{l}\text { Fears of occurring disasters in the } \\
\text { future }\end{array}$ & from none $=1$ to very big $=5$ \\
\hline & $\begin{array}{c}\text { Probability of occurring disasters } \\
\text { during next } 3 \text { to } 5 \text { years }\end{array}$ & from impossible $=1$ to certain $=5$ \\
\hline & $\begin{array}{l}\text { Perception of the frequency of } \\
\text { extreme weather events and } \\
\text { disasters occurrence in connection } \\
\text { with climate change }\end{array}$ & $\begin{array}{l}\text { from currently much lower number } \\
\text { of cases }=1 \text { to currently much } \\
\text { higher number of cases }=5\end{array}$ \\
\hline & Feeling of safety & $\begin{array}{l}\text { from I feel safely }=1 \text { to I don't feel } \\
\text { safely }=5\end{array}$ \\
\hline \multirow{4}{*}{ Knowledge, Awareness } & Hazard-prone areas awareness & yes $=1 /$ no $=0$ \\
\hline & Evacuation plan awareness & yes $=1 /$ no $=0$ \\
\hline & Warning signals awareness & $\begin{array}{l}\text { assigning correct answer (all well } \\
\text { recognized }=1, \text { not recognized }=0 \text { ) }\end{array}$ \\
\hline & Protection possibilities awareness & yes $=1 /$ no $=0$ \\
\hline
\end{tabular}

A combination of continuous, nominal, and ordinal response questions was presented. The answers were transformed to digital values for further research. In the framework of the basic respondents' characteristics, the nominal variables were transformed as follows: the particular place of living (urban $=0$; rural $=1$ ) and the economic situation (from 0 (no sufficient financial reserves for the recovery) 
to 5 (we have enough reserves, even for improving the current state), the transformation of further variables-see Table 1.

\subsection{Methods of Statistical Analysis}

First of all, the individual answers in the questionnaire were assessed by means of descriptive statistics: the percentage distribution or the mean, mode, and SD values. In order to achieve the research goal: to investigate the relations between the dependent variables (1) "Preventive and mitigation measures adopted" and (2) "Subjective assessment of own preparedness for disasters", and the explanatory variables, a bivariate correlation analysis using the Pearson's correlation (r) was carried out. This analysis enabled us to identify those variables that have a significant influence (individually) on the dependent variables. Those independent variables that statistically significantly affect the observed dependent variables $(p<0.05)$ were then investigated by the multiple regression analysis. The multiple regression model was used for inquiring into the predictors of the objective and subjective preparedness. Due to the fact the variable of the objective preparedness is dichotomous, and that of the subjective preparedness is an ordinal one, we used different forms of the regression analysis. The multiple regression model was used for the objective preparedness and the multiple linear regression model for the subjective preparedness. Multicollinearity among the explanatory variables for each model was assessed using tolerance values, variance inflation factors (VIFs), and using collinearity diagnostics (eigenvalues, condition index, and variance proportions).

\section{Results}

In the framework of the next sections, we summarize and discuss the results of the independent and dependent variables separately, at first, and subsequently, we will explain and discuss the results of the correlation and regression analysis.

\subsection{Descriptive Statistics}

\subsubsection{General Characteristics}

The males created $52.39 \%$ and females $47.61 \%$ of the respondent group. The average age was 29.3 years $(\mathrm{SD}=11.36)$ and the majority of the respondents were adult persons (not students, mostly employed people- $60.20 \%$ ) and the rest were students (39.8\%). This fact served as the basic point for comparing these two respondent categories. As to their location of living, the respondents were divided approximately equally (urban-51.64\%; rural-48.36\%). Based on a similar population distribution [59], it was possible to assess the influence of the environment the respondents are living in on their preparedness. On average, the respondents live with one disabled person or a person requiring an increased care (mean, $\mathrm{SD}=0.6,0.96$ ). The average is low; however, it is close to one person that requires care-this is confirmed by the fact that $39 \%$ of the respondents have at least one person like this in their household. From the point of view of the economic possibilities and reserves of the respondents-on average, they have enough means only for smaller to medium repairs after a negative event (mean, $\mathrm{SD}=2.25,0.88$ ). This situation cannot limit people in the case of realizing measures, also, before another event.

\subsubsection{Disaster Experience Variables}

The disaster experience- - the respondents have much experience from various disasters and extreme weather (floods $57 \%$, heavy hail or storms $68 \%$, snow calamities $55 \%$, forest fires $38 \%$, heat waves $70 \%$, whirlwinds, drought $66 \%$, landslides $24 \%$, and earthquakes $16 \%$ ). Moreover, $3 \%$ of the respondents experienced more than one event. We expected (and it was also confirmed) a relatively high proportion of experiencing floods and their impacts. However, the higher proportions of heat waves and drought surprised us. Based on these results, we can see where our investigation in the future is to be aimed at-especially at the extreme influences of the weather because our finding is 
inconsistent with the statistics by the Ministry of Interior [58] and the Slovak Hydrometeorological Institute [57].

The worst experience- the classification of the respondents according to the severity rate of the experienced impacts-is as follows: threat of life and health-18.01\%, major damages on property $-28.59 \%$, minor damages on property-25.02\%, the logistic complications- $28.3 \%$. The average score (including "none $=1$ ") is $3.36, \mathrm{SD}=1.42$. The severity of the experienced impacts is more than average, i.e., the floods cause relatively big damages mainly on the property.

The evacuation experience-the research showed that only $8 \%$ of the respondents had been evacuated in the past. It is a relatively low amount regarding the number of the experienced events. We can recognize here a connection with severity of the experienced events that are, as a rule, the initiator of the evacuation. According to the results the rate of threat of human life was lower and it was not necessary to realize any evacuation although the event caused material damages. There is assumption that this experience could at least affect the objective side of preparedness.

\subsubsection{Risk Perception Variables}

Table 2 shows the detected values of the variables investigated. The variables were evaluated individually by a scale from 1 to 5 (see the explanation in the Table 1). The total average score of the investigated variables for the risk perception was 3.16. It shows ambiguous expectations regarding other disasters in the future. As to the results regarding the experience, it is no surprise, because $57 \%$ of the respondents have experienced floods and, therefore, on average, they admit the possibility of repeated occurrence. It is similar with perceiving the risks of climate change-here, the value is a little higher, which can result from the influence of other experienced events (especially the heat wave and drought). The current results indicate a relation between the variables "Fears of occurring disasters in the future" and "Feeling of safety"-if people's fear from the further events is low, they will probably feel safe in their place of living, e.g., Pagneux et al. [60] say there are significant differences of these conceptions, and their influence on preparedness can vary, and, therefore, both variables were incorporated to the study; however, the differences can be confirmed by the correlation analysis.

Table 2. Risk perception variables evaluation.

\begin{tabular}{cc}
\hline Main Variables & Mean (SD) \\
\hline Fears of occurring disasters in the future & $2.25(0.81)$ \\
\hline $\begin{array}{c}\text { Probability of occurring disasters during next 3 to 5 years } \\
\text { in connection with climate change }\end{array}$ & $3.00(0.64)$ \\
\hline Feeling of safety & $3.31(0.89)$ \\
\hline
\end{tabular}

\subsubsection{Disaster Awareness Variables}

Almost a quarter of the respondents was aware of the fact they are living in a territory endangered by floods and approximately the same amount of respondents say they are informed about the possibility of protection against various types of threats. As to knowledge of the warning signals, similarly, about one quarter- $23 \%$ of respondents - correctly gave answers to the question. The awareness of a plan in the case of a potential evacuation is a little higher-almost $40 \%$ of the respondents. From the point of view of the investigated variables (except for the prone-zone awareness as it can be objective), the overall level of awareness of the risks of disasters is low. Insufficient knowledge was also detected in the previous works $[42,60]$. The given situation is according to the "Assessment of the Conceptual Development in the Area of Population Protection" in the field of the citizens' protection caused by the fact there are no initiatives, policies or strategies that would be oriented on the strategic development of the population preparedness in the Slovak Republic [22,61]. A certain effort can be recognized in the area of education at primary schools, but the extent is minimal [62-64]. 
It is necessary to add that the aspect "awareness" includes a lot of subjectiveness because the "correctness" of the following answers was not checked (except for the warning signals): if the respondents really live in the threatened territory or they only said it; if they are really able to implement the knowledge of the protection measures, and if they really know the evacuation procedures.

\subsubsection{Respondents' Disaster Preparedness (Objective) and Perceived Preparedness (Subjective)}

One-third of respondents prepared objectively for the further disasters and the remaining two-thirds did not prepare at all. The respondents were asked to say the ways of their preparation, but this part of the question was optional, and not all of them introduced exact forms of preparation, and so, it is not possible to evaluate them. However, the respondents said several times they created certain capacities (pumps, bags with sand, substitute energy sources, etc.), but also the structural preparation forms, e.g., adaptation of the estate and slopes, draining, protection of the assets, etc. The answers did not contain any forms of preparation in the form of plans and procedures according to Rusell et al. [29].

If we compare the quantity of the experienced events ( $57 \%$ of respondents experienced floods and more than $90 \%$ experienced any other disaster)—the rate of the objective preparedness based on this variable can be considered low. However, it is more relevant to compare it only with the floods because the severity of other disaster types is not that high (e.g., the snow calamities cause mostly only logistic problems that can be solved; the heat waves and droughts can be hardly reflected by any particular measures by the individual persons, etc.). The given differences should be analyzed more thoroughly.

The research participants were asked to assess their own preparedness for disasters in the future on a five-point scale, from 1 to $5(1=\mathrm{I}$ am not prepared at all $)$. The respondents perceive their preparedness as low up to average (Mean $=2.6$; SD $=1.01(1=15.87 \% ; 2=27.20 \% ; 3=41.44 \%$; $4=11.84 \% ; 5=3.65 \%$ ). The factors that affect this assessment were investigated in the framework of the correlation and regression analysis. However, the descriptive statistics of the independent variables indicate that the low awareness and negative experience should affect this situation. We can claim that the assessment of the objective preparedness is similar as to the level of the objective preparedness. Preparedness is more or less below-average.

\subsection{Factors Affecting the Objective and Subjective Preparedness—Correlation and Regression Analysis}

In the literature, a lot of variables that can be addressed within the disaster preparedness assessment can be found. Some studies confirm their influence on the preparedness, but some of them not. In order to select variables that principally affect the objective and subjective preparedness, we realized a correlation analysis in our study (see the Table 3). In the regression analysis, we used only those variables that have a statistically significant influence on preparedness $(p<0.05)$.

The correlation analysis showed that 11 variables were significantly correlated $(p<0.05)$ with the dependent variable "a" (the objective preparedness) and 13 variables were significantly correlated with the dependent variable " $\mathrm{b}$ " (the subjective perception of preparedness). The rate of dependence was very weak up to weak (according to Evans [65]). Only the variable- the worst experience (Pearson correlation coefficient $=0.44, p<0.01$ - -shows an average correlation level with the objective preparedness.

The majority of dependences was positive and it indicates (for the objective preparedness) that the preventive activities were accepted, if the independent variable achieved higher values, or in the case of the dichotomous values, 1 . The same is valid for the subjective assessment of preparedness and its higher level. The negative values indicate the opposite. 
Table 3. Pearson's Correlation between dependent variables ("a"- the objective disaster preparedness; " $b$ "- the subjective disaster preparedness) and independent variables.

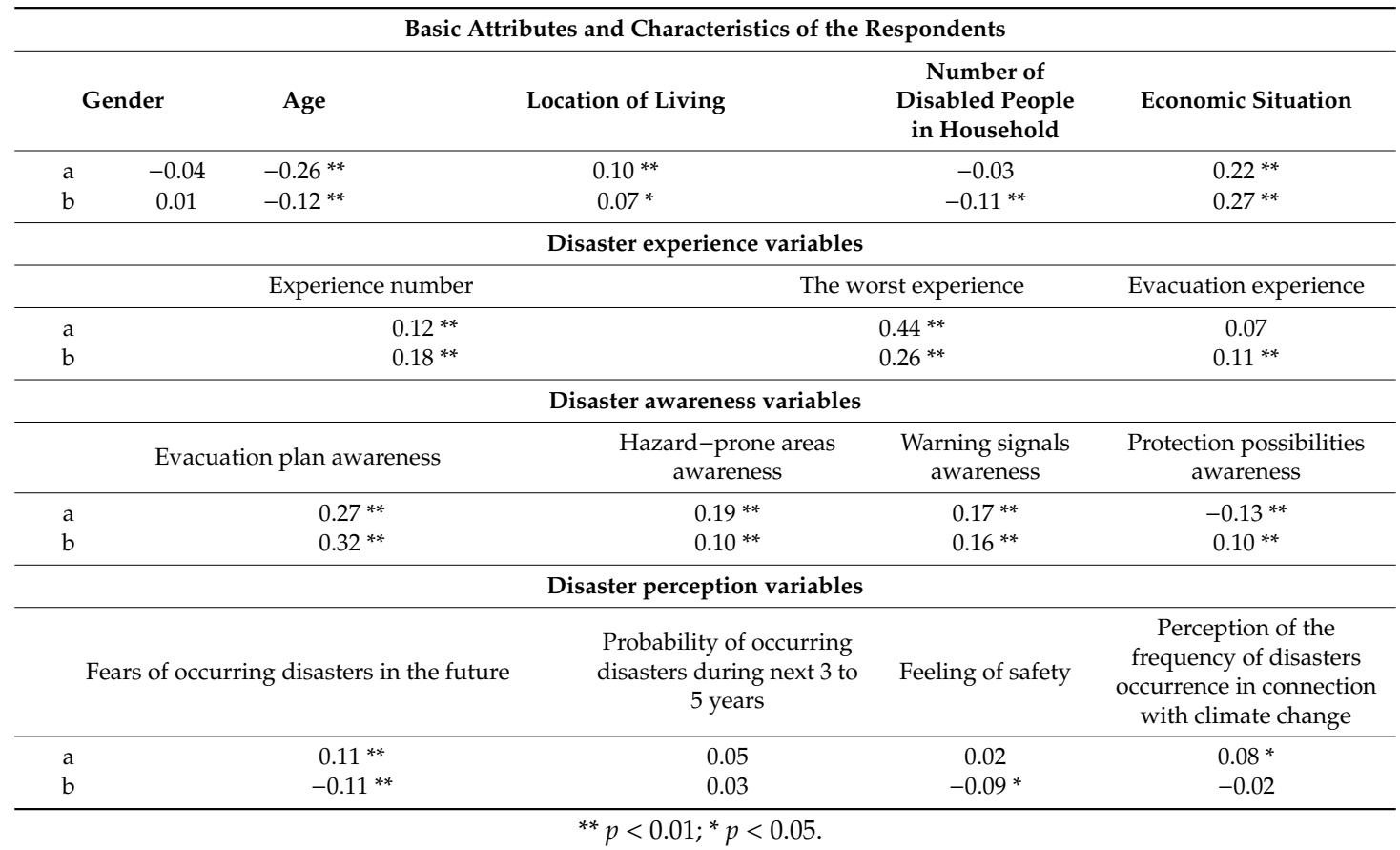

Based on the findings, multivariate regression models were fitted to predict adoption of preventive or mitigation measures and to predict perception of own preparedness level for future disasters (Tables 4 and 5).

Table 4. Multiple logistic regression model investigating variables relating to people's objective preparedness.

\begin{tabular}{|c|c|c|c|c|c|c|c|c|}
\hline \multirow{2}{*}{ Variables in the Equation } & \multirow{2}{*}{ B } & \multirow{2}{*}{ S.E. } & \multirow{2}{*}{ Sig. } & \multirow{2}{*}{$\begin{array}{l}\text { Exp. } \\
\text { (B) }\end{array}$} & \multicolumn{2}{|c|}{ 95\% C.I. for $\operatorname{Exp}(B)$} & \multirow{2}{*}{ Tolerance } & \multirow{2}{*}{ VIF } \\
\hline & & & & & Lower & Upper & & \\
\hline Age & -0.034 & 0.010 & $0.001^{* *}$ & 0.966 & 0.948 & 0.985 & 0.831 & 1.203 \\
\hline Location of living & 0.133 & 0.188 & 0.481 & 1.141 & 0.790 & 1.651 & 0.913 & 1.095 \\
\hline Economic situation & 0.295 & 0.098 & $0.003 * *$ & 1.343 & 1.108 & 1.628 & 0.895 & 1.117 \\
\hline Experience number & -0.229 & 0.093 & $0.014^{*}$ & 0.795 & 0.663 & 0.954 & 0.751 & 1.332 \\
\hline The worst experience & 0.572 & 0.075 & $0.000^{* *}$ & 1.771 & 1.528 & 2.053 & 0.671 & 1.490 \\
\hline Hazard-prone areas awareness & 0.600 & 0.223 & $0.007^{* *}$ & 1.823 & 1.177 & 2.823 & 0.811 & 1.232 \\
\hline Evacuation plan awareness & 0.862 & 0.150 & $0.000 * *$ & 2.369 & 1.767 & 3.175 & 0.868 & 1.152 \\
\hline $\begin{array}{c}\text { Protection possibilities } \\
\text { awareness }\end{array}$ & -0.696 & 0.278 & $0.012 *$ & 0.499 & 0.289 & 0.859 & 0.875 & 1.143 \\
\hline Warning signals awareness & 0.373 & 0.210 & 0.075 & 1.453 & 0.963 & 2.192 & 0.909 & 1.101 \\
\hline $\begin{array}{c}\text { Fears of occurring disasters in } \\
\text { the future }\end{array}$ & 0.080 & 0.096 & 0.406 & 1.083 & 0.897 & 1.3085 & 0.827 & 1.209 \\
\hline $\begin{array}{l}\text { Perception of the frequency of } \\
\text { disasters occurrence in } \\
\text { connection with climate change }\end{array}$ & 0.301 & 0.104 & $0.004^{* *}$ & 1.351 & 1.102 & 1.656 & 0.931 & 1.074 \\
\hline Constant & -3.626 & 0.586 & 0.000 & & & & & \\
\hline
\end{tabular}

B-regression coefficient; S.E.—standard error; C.I.—confidence interval; Sig.—significance; VIF-variance inflation factor; ${ }^{* *} p<0.01 ;{ }^{*} p<0.05$. 
Table 5. Multiple linear regression model investigating variables relating to people's subjective preparedness.

\begin{tabular}{|c|c|c|c|c|c|c|c|c|}
\hline \multirow{2}{*}{ Variables in the Equation } & \multirow{2}{*}{$\beta$} & \multirow{2}{*}{ S.E. } & \multirow{2}{*}{ t Stat } & \multirow{2}{*}{ Sig. } & \multicolumn{2}{|c|}{ 95\% C.I. } & \multirow[b]{2}{*}{ Tolerance } & \multirow{2}{*}{ VIF } \\
\hline & & & & & Lower & Upper & & \\
\hline Age & -0.003 & 0.003 & -0.878 & 0.380 & -.009 & 0.380 & 0.837 & 1.194 \\
\hline Location of living & 0.085 & 0.067 & 1.270 & 0.204 & -0.046 & 0.204 & 0.880 & 1.137 \\
\hline $\begin{array}{l}\text { Number of disabled people in } \\
\text { household (or with a need of } \\
\text { increased care) }\end{array}$ & -0.064 & 0.034 & -1.886 & 0.060 & -0.131 & 0.060 & 0.934 & 1.071 \\
\hline Economic situation & 0.190 & 0.035 & 5.502 & $0.000 * *$ & 0.122 & $0.000 * *$ & 0.876 & 1.142 \\
\hline Experience number & 0.067 & 0.032 & 2.121 & $0.034^{*}$ & 0.005 & $0.034^{*}$ & 0.749 & 1.334 \\
\hline The worst experience & 0.116 & 0.027 & 4.320 & $0.000 * *$ & 0.063 & $0.000 * *$ & 0.945 & 1.058 \\
\hline Evacuation experience & 0.149 & 0.117 & 1.279 & 0.201 & -0.080 & 0.201 & 0.662 & 1.510 \\
\hline Hazard-prone areas awareness & 0.045 & 0.082 & 0.547 & 0.584 & -0.116 & 0.584 & 0.807 & 1.240 \\
\hline Evacuation plan awareness & 0.387 & 0.053 & 7.317 & $0.000 * *$ & 0.284 & $0.000 * *$ & 0.859 & 1.164 \\
\hline $\begin{array}{l}\text { Protection possibilities } \\
\text { awareness }\end{array}$ & 0.293 & 0.089 & 3.276 & $0.001 * *$ & 0.117 & $0.001 * *$ & 0.866 & 1.155 \\
\hline Warning signals awareness & 0.069 & 0.078 & 0.887 & 0.375 & -0.084 & 0.375 & 0.905 & 1.105 \\
\hline $\begin{array}{l}\text { Fears of occurring disasters in } \\
\text { the future }\end{array}$ & -0.149 & 0.034 & -4.394 & $0.000 * *$ & -0.216 & $0.000 * *$ & 0.837 & 1.194 \\
\hline Feeling of safety & -0.061 & 0.038 & -1.596 & 0.111 & -0.135 & 0.111 & 0.880 & 1.137 \\
\hline Intercept & 1.660 & 0.238 & 6.972 & 0.000 & 1.193 & 0.000 & & \\
\hline
\end{tabular}

$\beta$-regression coefficient; S.E.—standard error; C.I.—confidence interval; Sig.- significance; ${ }^{* *} p<0.01 ;{ }^{*} p<0.05$.

The fact the VIFs did not exceed a value of 3 and the tolerance values were not below 0.1 , indicates that multicollinearity is minimal. This statement is also confirmed by the collinearity diagnostics. The condition index did not exceed 30 in either case. For one dimension the condition index exceed the value of 15 , but we did not find two variance proportions that would exceed the value of 0.9 , so there was no collinearity problem. Very similar results were observed for the linear model.

The results of the multiple regression analysis (see the Tables 4 and 5) indicated that 8 of 11 variables were significantly related to people's objective preparedness: age, economic situation, experience number, the worst experience, hazard-prone areas awareness, evacuation plan awareness, protection possibilities awareness, perception of the frequency of extreme weather events and disaster occurrence in connection with climate change); and 6 of 13 variables (economic situation, the worst experience, evacuation plan awareness, protection possibilities awareness, fears of occurring disasters in the future) were significantly related to people's subjective perception of preparedness.

\section{Discussion}

According to the results, preparedness (no matter if objective or subjective) is based rather on the experience of people from previous events (variables: experience number, the worst experience) and on risk awareness (variables: evacuation plan awareness, protection possibilities awareness). From the respondent's general characteristics, only "Economic situation in household" has a significant influence on both objective and subjective preparedness.

In this section, we will discuss the significant relationships between the preparedness and relevant variables, at first, and then we will focus on variables that affect only one side of preparedness. Finally, we will discuss the implications of our results for DRM and its sustainable development.

\subsection{Experience Influence on Preparedness}

Our findings suggest that people's preparedness is significantly related to their experience with disasters or extreme weather events. There is relation with the "number of disasters experienced" $(p<0.05)$ for both objective $(p=0.014)$ and subjective $(p=0.034)$ preparedness. A stronger relation can be seen between the dependent variables and "the worst experience" $(\mathrm{r}=0.44 ; p<0.001)$. The results indicate that the people's experience with a disaster is a starting point to adopt some prevention measures and, at the same time, this experience can result in higher self-confidence in dealing with a future disaster (they feel better prepared for a disaster). The negative side of experience plays an important role in people's behavior in the future. It can be assumed that a further disaster with 
serious consequences would arouse an active preparation for the disasters. We assume an individually active approach, but also an active approach within the community, and in building a resilient society. However, this assumption needs to be investigated more thoroughly.

Other facts show that the disaster type is an important factor that affects the results. A deeper analysis shows that the other disasters, except floods, do not have such a significant influence on the disaster preparedness. The investigation of the reasons for these differences requires in-depth research, but it can be assumed that it is caused, predominantly, by the major damages of the property caused mainly by the floods, and, vice versa, such damages occurred rarely in the case of other disasters in the Slovak territory. This fact shows big material damages, and even then (in a smaller extent), the threats of life and health are the predominant reasons for an active approach to strengthening safety.

Improvement of population preparedness through experience can be realized only indirectly (videos, analyses, studies) or by simulation in the form of various types of exercises (real and virtual ones) and, at the same time, it is possible to train certain procedures of behavior and realization of the protection measures [66]. In this way, it is then possible to motivate people for preventive measures (e.g., the structural measures) for them to be able to prevent stressful situations and situations that threaten lives and property when disaster effects develop. People living in the most vulnerable areas of the SR are involved in the preparation activities, in the framework of possible realization of the Population Protection Plan, which is worked out by the municipality in collaboration with the competent bodies. The Population Protection Plan contains tasks, measures, and procedures to ensure the protection of the population during the disaster [26,67]. This plan represents a suitable means for building society's resilience and implementing particular policies for strengthening this idea, but currently, the population's involvement into this plan is minimal, and it is trained only sporadically. The process of preparation and education in this area is not continuous and flexible and, therefore, it cannot reflect the changing environment and current development.

Notably, we can observe small discrepancies between the statistics of the major disasters in Slovakia and the subjective assessment of the seriousness of the consequences experienced by respondents. The subjective assessment (mean $=3.36$ from 5 ) implies that, on average, the respondents experienced from minor to major property damages, which is slightly overestimated compared to the statistics. Due to this fact, a certain bias of the results could take place. The understanding of the importance of the formative individual person's experience can contribute to grasping the circumstances, how people improve their preparedness rate, or it can be utilized in the framework of the information campaigns or discussions as a catalyst of the desirable behavior at the individual or collective level.

\subsection{Risk Awareness and Preparedness}

Population preparedness is remarkably affected by the respondents' knowledge and particularly by the guideline awareness (e.g., the evacuation guidelines) and protection possibilities awareness. From the point of view of preparedness, it is obvious that just awareness and knowledge of the protection possibilities and procedures that will have to be followed can principally help prevent, solve, and also support the activity during the recovery after the event, effectively. The results of the correlation analysis and regression model confirm this fact for the area of subjective preparedness-as Badura claims the perception of our preparedness is strengthened by being aware of our abilities to reach the required goal (the self-efficacy) [44]. However, it is paradoxical that, according to the results, the protection possibilities awareness has a negative link with the objective preparedness $(r=-0.13$; $\mathrm{B}=-0.696$ ). This fact indicates that the respondents have already heard about the given topic and the protection possibilities, but in spite of this, or because of that, they did not prepare for the next events. It is possible the recommended measures were not relevant for them and they consider them little effective. Due to this fact, they will rely on the emergency units. They can lie in an insufficient quality of information that the respondents obtained (the quality of the information campaign and education). The education and training in the area of protecting against disasters (self-protection) of the adults is predominantly based on their own initiative and motivation. The education is realized 
only at the basic schools, and partially at the secondary schools in the framework of some subjects (e.g., physics, civics, physical training), and the transferred knowledge from this period can be already distorted. The next reason can be connected with credibility of the sources and authorities that are emphasized especially in connection with the risks of climate change. The credibility of the authorities, sources, and communication channels can principally influence the public's view at the given area [45]. The suitably selected communications of this area with the general public has to be considered appropriately. The detected results confirm importance, need, and effect of the information campaign, continual education, and the process of increasing awareness of preparedness [42]. This information can serve as a basis for developing DRM and optimizing the conceptions and strategies of the education development, and involvement of the society to this system.

It is a long-term task to strengthen the disaster awareness on a blanket basis. It requires a systematic approach, maintaining the continuity of this process and a suitable adjustment from the point of view of the content. The feasibility of these activities is, therefore, determined by the strategic and conceptual decisions (especially in the area of education) and support of the sustainable development of the DRM system. From the strategic point of view, this issue is more or less solved by initiatives aimed at preparing the children as a strategic solution for development of future generations [68-70]. Only time will show the effectiveness of these initiatives. In the Slovak Republic, these initiatives are not respected sufficiently at all. However, currently, there are governmental efforts to change the routine system (for now with no clear realization plan). The position of the young people and adults is even a little more complicated. The preparation of youth and adults for disaster protection is carried out by the district offices, legal entities, natural persons-entrepreneurs, self-governing regions, municipalities, and humanitarian associations (Slovak Red Cross, Office of Civil Protection of the SR) [26]. From the population point of view, the municipality plays an important role in addressing preparedness or building resilience, as it is the primary point of contact in the terms of subsidiarity. The content and form of the population preparedness for disasters and emergencies is chosen by the municipality itself [27]. These are usually training sessions, discussions, workshops, meetings, seminars, competitions of young rescuers, demonstrations of rescue techniques and rescue activities, as well as local TV programs. The non-systematic approach or strategic educational framework, increasing awareness or resilience against disasters' consequences is determined for this group of population in the area of preparation and protection against disasters. Currently, it seems suitable to strengthen the position of the local crisis management offices and, thus, the task of the aforementioned Population Protection Plan, whose regular training represents the strengthening of the knowledge basis of people in the given place, as well as their practical skills. However, such a solution can encounter (also in other countries) the personal and financial problems concerning the provision of these trainings and also their effectiveness.

Generally in Slovakia, the influence of the awareness aspect is significant on both dependent variables, although the rate of awareness is low. This fact can be a strong, supporting argument for supporting the activities oriented on increasing population awareness, especially when we aim at the more vulnerable groups of inhabitants and particular localities.

\subsection{Influence of Economic Situation on Preparedness}

Economic situation was the only statistically significant factor $(p<0.01)$ relevant for both objective and subjective preparedness, within general attributes affecting preparedness. The financial cost of adopting preventive measures against disaster effects is mostly high. People tend to spend money on preventive action only if they are highly exposed to a risk or when they have extra resources at disposal. This conjecture finds support in our research and also in some others [71,72]; however, several studies do not confirm this relationship (e.g., [47]).

The present result is also consistent with the evidence that people who perceive their financial resources as adequate for coping with consequences and for recovery are more confident about their self-preparedness [73]. This can have a significant mitigating effect on the effects of the future events. 
The achieved results explain the high costs of some measures, e.g., against floods. The financial costs for strengthening the building structure or the estates against floods can be high. However, some measures can be carried out for lower expenses, e.g., preparing the emergency supplies, storing important objects at a higher floor or blocking the building entrances. Tierney indicates that the difference of the measures taken depends on the socio-economic status of the given population and, at the same time, various types of preparation assume the knowledge of adequate measures and ability to join the self-protection activities before the event [71]. Social inequality plays an important role, not only for the ability to take financially different measures, but also for the possibility to gain information and strengthen risk awareness, and also awareness of the selected population [71]. Chapman et al. shows that, if we want to motivate towards the change of behavior, e.g., in the form of an increased engagement rate, it is necessary to give the information in regard to the type of the audience, and to adapt the information for the given people [54]. Of course, the given problem is closely connected with the already discussed part dealing with strengthening society's awareness of the risks and disasters. Research on the relation between objective preparedness and economic situation on a sample of respondents who were aware of the fact they were living in an endangered territory $(\mathrm{n}=191)$ showed that the relation was even stronger $(\mathrm{r}=0.28 ; p<0.01)$. Similarly, the strength of dependence for the subjective preparedness and economic situation was changed $(\mathrm{r}=0.33 ; p<0.01)$. It indicates that the awareness, in combination with sufficient resources, can significantly affect objective preparedness, and, at the same time, strengthen the subjective perception of our preparedness.

The economic situation of a family depends on plenty of factors that are connected with the individual's capabilities. The economic status of the population (especially the vulnerable groups) can be achieved through supporting programs and targeted aid. However, it is impossible to expect that, also, their preparedness will proportionally increase. Strengthening the population's awareness of possible threats and suitable protection methods seems to be more relevant.

\subsection{Variables Affecting Only One Side of Preparedness}

The important predictors (besides the discussed ones) important for the objective preparedness are: age, hazard-prone areas awareness, and perception of the frequency of extreme weather events and disaster occurrences in connection with climate change.

According to the results, younger people incline more to realizing the protection measures. This finding can be partially surprising, but the cause can be found in a more active approach of the young people, the ability to solve problems, and their higher awareness of threats. Closer research of the relation age-preparedness confirms this fact. The correlation dependence of the age and objective preparedness increased to $\mathrm{r}=-0.34, p<0.01$ and the dependence of the age and the subjective preparedness increased to $r=-0.16, p<0.01$. The younger respondents also assess their preparedness on average higher that the older ones. However, the regression analysis did not confirm any significant relation of the age and subjective preparedness.

The knowledge that people are living in an area endangered by floods was a significant predictor for realizing the protection measures, according to the correlation and regression analysis. The difference can be revealed in people's skepticism regarding the suitability of the measures adopted. The measures themselves sometimes need not be sufficient for a certain type of threat or can be sufficient only for certain situation seriousness. This fact results from the stochastic nature of the threat itself and its various types of demonstrations. It means the inhabitants, even in the case they took certain measures (increasing the objective preparedness), are not sure they are sufficient, or they are aware of this fact. As the individual measures taken were not investigated in depth, there can be moderate deviations regarding the influence on the objective preparedness.

There is plenty of information concerning climate change activities, on the environment and society, but there is less of it about the possibilities and methods on how to protect against its influence. In spite of this, people perceive this threat and try to respond to it. A positive relation was confirmed only in connection to objective preparedness. The reasons can be found in the need to protect especially 
against the weather influences (storms and torrential rains) whose frequency and impacts are multiplied just by climate change. However, people are preparing for these influences in the threatened territories anyway (confirmed by the analysis results). It is difficult to confirm climate change as the reason of the protection behavior, because people simultaneously perceive it as difficult to prepare for, performing other types of extreme weather, e.g., drought or heat waves.

The factor-fears of occurring disasters in the future-is, according to the regression model, the only factor that affects the subjective perception of the population preparedness $(p<0.01 ; \beta=-0.149)$ most significantly (besides the common ones). The relation is negative and it indicates that, with the growing fear, the perception level of our preparedness declines. The relation is logical because people are afraid of things they are not prepared for, or, for those, they are not able to prepare due to the nature of the threat or insufficient means [60].

\subsection{Implications for Disaster Risk Management}

The research results emphasize that the strengthening of the objective and subjective preparedness is affected by the economic possibilities of the households, the experience with disasters, and the population's awareness level about disasters. The addressing of the population awareness is considered the basic point towards the possible change to a sustainable DRM system. For us to increase this awareness it is inevitable to emphasize the role of the individual person and the whole society in the system of preventing and solving the crisis phenomena. The educational campaigns should emphasize the personal responsibility of individuals for self-protection and, at the same time, their important role in the framework of the society. Indisputably, it is important for the population to receive sufficient relevant information about the possibilities of protection, particularly in the context of climate change. The possibilities of protection should be offered with regard to the individual possibilities of people because, as the research showed, the realization of some measures could be a problem for the more economically vulnerable groups. The outputs of the active approach (engagement) of the individual persons in the framework of the society for achieving the common goal should be emphasized. The removal of the economic barriers and creation of a solidarity environment represent a potential for developing sustainable development of DRM, as well as security of the whole society.

It is not simple to address these factors especially due to the interdisciplinary nature of preparing the population for disasters. The solution requires at least a link of the crisis management system with the educational system. As we have mentioned already, the preparation in the investigated area actually ends at the second grade of the basic schools, and it is insufficient nowadays. In connection with climate change, the tools and methods of communication with the general public are coming to the foreground. Therefore, the next interest of the investigators is to investigate the possibilities of an effective link of these systems with the goal to strengthen the overall resistance of the population against the possible risks connected with climate change. Some of the recent studies suggest that interpersonal factors also need to be considered when understanding people's disaster preparedness [74,75]. It seems to be an important perspective regarding the engagement of the population into disaster preparedness activities because there can be substantial incongruence between household members (regarding shared responsibility or common opinion) [74,75]. These differences need to be further explored and this topic can be an important issue for the further research.

This study investigated the objective and subjective side of the population preparedness for disasters. In the framework of the objective preparedness, the findings are limited by the fact whether the inhabitants accepted the protection measures. Due to the low amount of the introduced particular measures, it was not possible to assess their adequacy, complexity, or demandingness of their implementation. However, the results provide information about the willingness of people to protect themselves and their relatives. This is a principal precursor of the possible engagement of the community or society-wide basis, and to participate in individual measures, as well as in collective ones. 


\section{Conclusions}

The Slovak government does not investigate the determinants of disaster preparedness for the population. This research, thus, helps acquire a picture about the important factors that influence the preparedness of the population for disasters in Slovakia. In our opinion, these facts are to be reflected in the framework of creating and realizing the conceptual measures in the area of preparing the Slovak population or people abroad because they are in compliance with other studies. The contribution of this study is the fact that it reflects, simultaneously, the objective and subjective side of preparedness-this was separated in previous studies. The link of these two constructs was confirmed in several respects. In this way, it is possible to support realizing the particular measures as well as the self-confidence of people in their capabilities to cope with disasters in the future.

The research results indicate that improvement of the economic situation of households, providing information from the past, and strengthening risk and disaster awareness, and adequate procedures for their solutions, are those factors that have the most principal influences on preparedness level. Changes toward the adjustment of these factors have to be supported by institutional changes, adaptation of regulations, and strategies that will enable people, strengthening individual resistance against disasters, and, subsequently, make the collective orientation of preparing for climate change risks better. It is important to draw attention to the local impacts connected with climate change, and link them with political, public, health, agricultural, and other problems of the region and country. To highlight the local demonstration of the climate crisis and its connections with the life of each individual means, possibly, to take a personal stance on this issue. We perceive this as the first step to arouse the interest of the public in implementing solutions that could moderate the risks resulting from the increase of the extreme events. Directly, the DRM system, as well as the initiatives aimed at the society, security, and its sustainable development, can benefit from the engagement of the society in the area of climate change and protection against its impacts.

Author Contributions: M.T. and J.R. conceived and designed the study; M.T. performed the experiment and data collection; all authors contributed to data analyses; all authors wrote the paper. All authors have read and agreed to the published version of the manuscript.

Funding: This research received no external funding.

Acknowledgments: Publication of this paper was supported by the Scientific Grant Agency of the Ministry of Education, Science, Research and Sport of the Slovak Republic-VEGA No. 1/0805/18 Establishing the principles and sequence of steps to measure the awareness and preparedness of the population to the risks of natural disasters. Publication of this paper was supported by the Scientific Grant Agency: The project KEGA No. 030ŽU-4/2018-Research of Risk Management in Enterprises in Slovakia to create a new study program Risk Management for the FBI University of Zilina.

Conflicts of Interest: The authors declare no conflict of interest.

\section{References}

1. Sandanam, A.; Diedrich, A.; Gurney, G.G.; Richardson, T.D. Perceptions of Cyclone Preparedness: Assessing the Role of Individual Adaptive Capacity and Social Capital in the Wet Tropics, Australia. Sustainability 2018, 10, 1165. [CrossRef]

2. Stephan, C.; Norf, C.; Fekete, A. How "Sustainable" are Post-disaster Measures? Lessons to Be Learned a Decade After the 2004 Tsunami in the Indian Ocean. Int. J. Disaster Risk Sci. 2017, 8, 33-45. [CrossRef]

3. Sineiro, C.C.; Ferreyra, Y.M.; Astudillo, D.; Soldá, S. Sustainability and risk management. Response, repair and prevention against floods from a case analysis. Let. Verdes. Rev. Latinoam. Estud. Socioambientales 2018, 24, 105-123. [CrossRef]

4. United Nations Office for Disaster Risk Reduction. Sendai Framework; United Nations Office for Disaster Risk Reduction: Geneva, Switzerland, 2015.

5. The International Federation of Red Cross and Red Crescent Societies. Disaster Risk Management Policy. 2020. Available online: https://media.ifrc.org/ifrc/wp-content/uploads/sites/5/2020/04/DRM_policy_Final_EN.pdf (accessed on 17 July 2020). 
6. Intergovernmental Panel on Climate Change. Managing the Risks of Extreme Events and Disasters to Advance Climate Change Adaptation: Special Report of Working Groups I and II of the Intergovernmental Panel on Climate Change; Cambridge University Press: Cambridge, UK, 2012; pp. 1-582.

7. European Environment Agency. Climate Change, Impacts and Vulnerability in Europe 2016-An Indicator-Based Report; EEA Report 1/2017; Publications Office of the European Union: Luxembourg, 2017; Available online: https://www.eea.europa.eu/publications/climate-change-impacts-and-vulnerability2016/at_download/file (accessed on 20 July 2020).

8. Bouwer, L.M. Have Disaster Losses Increased Due to Anthropogenic Climate Change? Bull. Am. Meteorol. Soc. 2011, 92, 39-46. [CrossRef]

9. Groenemeijer, P.; Vajda, A.; Lehtonen, I.; Kämäräinen, M.; Venäläinen, A.; Gregow, H.; Becker, N.; Nissen, K.; Ulbrich, U.; Nápoles, O.M.; et al. Present and Future Probability of Meteorological and Hydrological Hazards in Europe. D2.5 Report, RAIN Project. 2016. Available online: http://rain-project.eu/wp-content/uploads/2016/ 09/D2.5_REPORT_final.pdf (accessed on 10 July 2020).

10. Guo, Y.; Gasparrini, A.; Li, S.; Sera, F.; Vicedo-Cabrera, A.M.; Coelho, M.D.S.Z.S.; Saldiva, P.H.N.; Lavigne, E.; Tawatsupa, B.; Punnasiri, K.; et al. Quantifying excess deaths related to heatwaves under climate change scenarios: A multicountry time series modelling study. PLoS Med. 2018, 15, e1002629. [CrossRef]

11. Luskova, M.; Dvorak, Z.; Leitner, B. Impact of Extreme Weather Events on Land Transport Infrastructure. Transport Means-Proceedings of the International Conference. Transp. Means. 2015, 19, 306-309.

12. Disaster Risk Management for Sustainable Development. CGSS/USM. Available online: https://en.unesco. org/greencitizens/stories/disaster-risk-management-sustainable-development (accessed on 15 August 2020).

13. Rehak, D.; Senovsky, P.; Hromada, M.; Lovecek, T. Complex approach to assessing resilience of critical infrastructure elements. Int. J. Crit. Infrastruct. Prot. 2019, 25, 125-138. [CrossRef]

14. Blokland, P.J.; Reniers, G. Safety Science, a Systems Thinking Perspective: From Events to Mental Models and Sustainable Safety. Sustainability 2020, 12, 5164. [CrossRef]

15. Climate-Smart Disaster Risk Reduction. Helping Communities Reduce Their Risks, Protect Themselves and Prepare for Emergencies. IFRC Report. 2020. Available online: https://media.ifrc.org/ifrc/wp-content/uploads/sites/5/ 2020/03/Climate-smart-DRR-IFRC-2020.pdf (accessed on 15 August 2020).

16. Sarabia, M.M.; Kägi, A.; Davison, A.C.; Banwell, N.; Montes, C.; Aebischer, C.; Hostettler, S. The challenges of impact evaluation: Attempting to measure the effectiveness of community-based disaster risk management. Int. J. Disaster Risk Reduct. 2020, 49, 101732. [CrossRef]

17. Oxfam and ADPC. Handbook: Community-Based Disaster Risk Management for Sindh Province, Pakistan; Asian Disaster Preparedness Centre: Bangkok, Thailand, 2014.

18. Ryan, B.; Johnston, K.A.; Taylor, M.; Mcandrew, R. Community engagement for disaster preparedness: A systematic literature review. Int. J. Disaster Risk Reduct. 2020, 49, 101655. [CrossRef]

19. Islam, E.; Wahab, H.A.; Benson, O.G. Structural and operational factors as determinant of meaningful community participation in sustainable disaster recovery programs: The case of Bangladesh. Int. J. Disaster Risk Reduct. 2020, 50, 101710. [CrossRef]

20. Deria, A.; Ghannad, P.; Lee, Y.-C. Evaluating implications of flood vulnerability factors with respect to income levels for building long-term disaster resilience of low-income communities. Int. J. Disaster Risk Reduct. 2020, 48, 101608. [CrossRef]

21. Antronico, L.; De Pascale, F.; Coscarelli, R.; Gullà, G. Landslide risk perception, social vulnerability and community resilience: The case study of Maierato (Calabria, southern Italy). Int. J. Disaster Risk Reduct. 2020, 46, 101529. [CrossRef]

22. Ministry of the Interior of the SR. Report of the Ministry of the Interior of the SR. Evaluation of the Fulfilment of the Tasks of the Concept of Organization and Development of Civil Protection by 2015. Available online: https://www.minv.sk/?Dokumenty_na_stiahnutie_CO (accessed on 15 February 2020).

23. Šimák, L. Crisis Management in Public Administration. In Crisis Management I. Theory of Crisis Management; EDIS: Žilina, Slovakia, 2004.

24. Schneider, M. The quality of life in large American cities: Objective and subjective social indicators. Soc. Indic. Res. 1975, 1, 495-509. [CrossRef]

25. The International Federation of Red Cross and Red Crescent Societies. Disaster Risk Reduction Information Sheet. Available online: https://media.ifrc.org/ifrc/wp-content/uploads/sites/5/2018/03/IDL-InformationSheet-No.2-DRR-February-2018.pdf (accessed on 14 July 2020). 
26. Act of the National Council of the Slovak Republic No. 42/1994 Coll. on Civil Protection. Available online: https://www.slov-lex.sk/pravne-predpisy/SK/ZZ/1994/42/20200409 (accessed on 15 July 2020).

27. Decree of the Ministry of Interior of the Slovak Republic 303/1996 Coll. to Ensure Preparation for Civil Protection. Available online: https://www.slov-lex.sk/pravne-predpisy/SK/ZZ/1996/303/20120301 (accessed on 15 July 2020).

28. Kitagawa, K. Exploring 'everyday-life preparedness': Three case studies from Japan. Int. J. Disaster Risk Reduct. 2019, 34, 265-274. [CrossRef]

29. Russell, L.A.; Goltz, J.D.; Bourque, L.B. Preparedness and Hazard Mitigation Actions before and after Two Earthquakes. Environ. Behav. 1995, 27, 744-770. [CrossRef]

30. United Nations Office for Disaster Risk Reduction. UNISDR Terminology for Disaster Risk Reduction; United Nations Office for Disaster Risk Reduction: Geneva, Switzerland, 2009.

31. Blanchi, R.; Leonard, J. Property Safety: Judging Structural Safety; Handmer, J., Haynes, K., Eds.; Community Bushfire Safety, Bushfire Co-operative Research Centre: Melbourne, Australia, 2008; pp. 77-85.

32. De Lopez, T.; Elliott, M.; Armstrong, A.; Lobuglio, J.; Bartram, J. Technologies for Climate Change Adaptation: The Water Sector-TNA Guidebook Series; UNEP: Roskilde, Denmark, 2011.

33. Ardaya, A.B.; Evers, M.; Ribbe, L. What influences disaster risk perception? Intervention measures, flood and landslide risk perception of the population living in flood risk areas in Rio de Janeiro state, Brazil. Int. J. Disaster Risk Reduct. 2017, 25, 227-237. [CrossRef]

34. Niwa, Y.; Burgess, A.; Ito, K. Questionnaire Study on the Relationship Between Disaster Awareness and the Recognition of Evacuation Points. Urban Reg. Plan. Rev. 2018, 5, 43-66. [CrossRef]

35. Mayunga, J.S. Understanding and applying the concept of community disaster resilience: A capital-based approach. Summer Acad. Soc. Vulnerability Resil. Build. 2007, 1, 1-16.

36. Linnerooth-Bayer, J.; Mechler, R.; Hochrainer-Stigler, S. Insurance against losses from natural disasters in developing countries: Evidence, gaps and the way forward. J. Integr. Disaster Risk Manag. 2011, 1, 59-81. [CrossRef]

37. Yang, F.; Tan, J.; Peng, L. The effect of risk perception on the willingness to purchase hazard insurance-A case study in the Three Gorges Reservoir region, China. Int. J. Disaster Risk Reduct. 2020, 45, 101379. [CrossRef]

38. Roder, G.; Hudson, P.; Tarolli, P. Flood risk perceptions and the willingness to pay for flood insurance in the Veneto region of Italy. Int. J. Disaster Risk Reduct. 2019, 37, 101172. [CrossRef]

39. Xu, H.; Li, Y.; Wang, L. Resilience Assessment of Complex Urban Public Spaces. Int. J. Environ. Res. Public Health 2020, 17, 524. [CrossRef]

40. Kusumastuti, R.D.; Husodo, Z.A.; Suardi, L.; Danarsari, D.N. Developing a resilience index towards natural disasters in Indonesia. Int. J. Disaster Risk Reduct. 2014, 10, 327-340. [CrossRef]

41. Cutter, S.L. Living with Risk; Routledge: New York, NY, USA, 1993.

42. Diakakis, M.; Priskos, G.; Skordoulis, M. Public perception of flood risk in flash flood prone areas of Eastern Mediterranean: The case of Attica Region in Greece. Int. J. Disaster Risk Reduct. 2018, 28, 404-413. [CrossRef]

43. Odiase, O.; Wilkinson, S.; Neef, A. Risk of a disaster: Risk knowledge, interpretation and resilience. Jàmbá J. Disaster Risk Stud. 2020, 12, 845. [CrossRef] [PubMed]

44. Bandura, A.; Caprara, G.V.; Barbaranelli, C.; Regalia, C.; Scabini, E. Impact of Family Efficacy Beliefs on Quality of Family Functioning and Satisfaction with Family Life. Appl. Psychol. 2011, 60, 421-448. [CrossRef]

45. Barinková, K.; Mesárošová, A. Self Efficacy. Psychologie a Její Context [Psychology and Its Context]. 2011. Available online: https://psychkont.osu.cz/fulltext/2011/Barinkova,Mesarosova_2011_2.pdf (accessed on 22 June 2020).

46. Simpson, D.M.; Katirai, M. Indicator Issues and Proposed Framework for a Disaster Preparedness Index. 2006. Available online: http://www.fritzinstitute.org/PDFs/WhitePaper/DaveSimpsonIndicatorsRepor.pdf (accessed on 17 August 2020).

47. Shapira, S.; Aharonson-Daniel, L.; Bar-Dayan, Y. Anticipated behavioral response patterns to an earthquake: The role of personal and household characteristics, risk perception, previous experience and preparedness. Int. J. Disaster Risk Reduct. 2018, 31, 1-8. [CrossRef]

48. Paton, D.; Smith, L.; Johnston, D. When good intentions turn bad: Promoting natural hazard preparedness. Aust. J. Emerg. Manag. 2005, 20, 25.

49. Onuma, H.; Shin, K.J.; Managi, S. Household preparedness for natural disasters: Impact of disaster experience and implications for future disaster risks in Japan. Int. J. Disaster Risk Reduct. 2017, 21, 148-158. [CrossRef] 
50. Goodie, A.S.; Sankar, A.R.; Doshi, P. Experience, risk, warnings, and demographics: Predictors of evacuation decisions in Hurricanes Harvey and Irma. Int. J. Disaster Risk Reduct. 2019, 41, 101320. [CrossRef]

51. Floyd, D.L.; Prentice-Dunn, S.; Rogers, R.W. A Meta-Analysis of Research on Protection Motivation Theory. J. Appl. Soc. Psychol. 2000, 30, 407-429. [CrossRef]

52. Neuwirth, K.; Dunwoody, S.; Griffin, R.J. Protection Motivation and Risk Communication. Risk Anal. 2000, 20, 721-734. [CrossRef] [PubMed]

53. Baker, E.J. Hurricane evacuation behavior. Int. J. Mass Emergencies Disasters 1991, 9, 287-310.

54. Chapman, D.A.; Lickel, B.; Markowitz, E.M. Reassessing emotion in climate change communication. Nat. Clim. Chang. 2017, 7, 850-852. [CrossRef]

55. Knuth, D.; Kehl, D.; Hulse, L.; Schmidt, S. Risk Perception, Experience, and Objective Risk: A Cross-National Study with European Emergency Survivors. Risk Anal. 2013, 34, 1286-1298. [CrossRef] [PubMed]

56. Lin, S.; Shaw, D.; Ho, M.-C. Why are flood and landslide victims less willing to take mitigation measures than the public? Nat. Hazards 2007, 44, 305-314. [CrossRef]

57. Climatic conditions of the Slovak Republic. The Slovak Hydrometeorological Institute. Available online: http://www.shmu.sk/sk/?page=1064 (accessed on 19 July 2020).

58. Ministry of Interior of the Slovak Republic. Report: Crisis Events Statistics (2013-2019); Ministry of Onterior of the Slovak Republic: Bratislava, Slovakia, 2020.

59. Statistical Office of the Slovak Republic. Population by Sex-SR, Regions, Counties, Districts, City, Countryside (Annually). Available online: http://statdat.statistics.sk/cognosext/cgi-bin/ (accessed on 12 August 2020).

60. Pagneux, E.; Gísladóttir, G.; Jónsdóttir, S. Public perception of flood hazard and flood risk in Iceland: A case study in a watershed prone to ice-jam floods. Nat. Hazards 2010, 58, 269-287. [CrossRef]

61. Ministry of the interior of the SR. Report on the activities of the Fire and Rescue Corps in 2019. Available online: https://www.minv.sk/?hasici-zachranari (accessed on 10 January 2020).

62. Sventekova, E.; Lusková, M. Project-Based Teaching as a Tool for Better Prepared Graduates in the Area of Security and Safety. In Proceedings of the 10th International Conference of Education, Research and Innovation (ICERI2017), Seville, Spain, 16-18 November 2017; pp. 984-988.

63. Soltes, V.; Kubás, J.; Štofková, K.R. Motivation of Students in Education in the Field of Security Management. In Proceedings of the 12th International Technology, Education and Development Conference, INTED, Valencia, Spain, 5-7 March 2018; pp. 9331-9337.

64. Hudakova, M.; Mika, V.; Masar, M. The current need of education in the field of risk management. In Proceedings of the 9th International Conference on Education and New Learning Technologies (EDULEARN17), Barcelona, Spain, 3-5 July 2017; pp. 819-827.

65. Evans, J.D. Straightforward Statistics for the Behavioral Sciences; Brooks/Cole Publishing: Pacific Grove, CA, USA, 1996.

66. Hudáková, M.; Buganová, K.; Dvorský, J. Increasing Integration of Practical Activities to the Higher Education in the Risk Management in Slovakia. In Proceedings of the 10th International Conference of Education, Research and Innovation (ICERI2017), Seville, Spain, 16-18 November 2017; pp. 996-1003.

67. Holla, K.; Mitašová, V.; Pavlenko, T. Risk Assessment Model Verification in Hazardous Industrial Processes. Procedia Eng. 2017, 192, 324-329. [CrossRef]

68. Tatebe, J.; Mutch, C. Perspectives on education, children and young people in disaster risk reduction. Int. J. Disaster Risk Reduct. 2015, 14, 108-114. [CrossRef]

69. Back, E.; Cameron, C.; Tanner, T. Children and Disaster Risk Reduction: Taking Stock and Moving Forward. 2009. Available online: https://www.preventionweb.net/files/15093_12085ChildLedDRRTakingStock1.pdf (accessed on 13 March 2020).

70. Tarazona, M.; Gallegos, J. Recent Trends in Disaster Impacts on Child Welfare and Development 1999-2009. Global Assessment Report on Disaster Risk Reduction, London, UK: Children in a Changing Climate. 2011. Available online: http://www.preventionweb.net/preventionwebfiles/english/hyogo/gar/2011/en/bgdocs/ Tarazona_\&_Gallegos_2010.pdf (accessed on 20 August 2020).

71. Tierney, K. Social Inequality, Hazards, and Disasters. On Risk and Disaster: Lessons from Hurricane Katrina; University of Pennsylvania Press: Philadelphia, PA, USA, 2006; pp. 109-128.

72. Lindell, M.K.; Prater, C.S.; Wu, H.C.; Huang, S.K.; Johnston, D.M.; Becker, J.S.; Shiroshita, H. Immediate behavioral response to earthquakes in Christchurch, New Zealand, and Hitachi, Japan. Disasters 2015, $41,85-111$. 
73. Levac, J.; Toal-Sullivan, D.; O'Sullivan, T.L. Household Emergency Preparedness: A Literature Review. J. Community Health 2011, 37, 725-733. [CrossRef]

74. Seebauer, S.; Fleiß, J.; Schweighart, M. A Household Is Not a Person: Consistency of Pro-Environmental Behavior in Adult Couples and the Accuracy of Proxy-Reports. Environ. Behav. 2016, 49, 603-637. [CrossRef] [PubMed]

75. Hung, L.-S. Comparing spousal agreement on perceived responsibility for household natural hazard preparedness to actual behavior. PLoS ONE 2019, 14, e0221217. [CrossRef]

Publisher's Note: MDPI stays neutral with regard to jurisdictional claims in published maps and institutional affiliations.

(C) 2020 by the authors. Licensee MDPI, Basel, Switzerland. This article is an open access article distributed under the terms and conditions of the Creative Commons Attribution (CC BY) license (http://creativecommons.org/licenses/by/4.0/). 